\title{
Effective language in study guides at a distance learning institution: Bridging the gap between the academic and non-academic cultures
}

\author{
Malvin Vergie \\ Language Services, University of South Africa, South Africa \\ E-mail: mvergie@unisa.ac.za
}

\begin{abstract}
This article explores the role of effective language in study guides in bridging the gap between the academic culture represented by lecturers and the non-academic culture represented by students at a distance learning institution (DLI). The study guide has to facilitate the student in the world of a new and sometimes intimidating culture, namely the (tertiary) academic culture. When lecturers write for students, they must have an understanding of the challenges facing distance learning students and write in clear, accessible language. There is little or no face-to-face contact between lecturers and students at a DLI, and teaching takes place mainly by means of printed study material, specifically study guides. However, many students may have trouble understanding the type of language used in study material - essentially, academic language sometimes because lecturers may not have an understanding of the challenges faced by students at a DLI and/or because they are used to writing in a formal, academic style, which is often not easily accessible to first-year students. The aim of the article is thus to identify the linguistic criteria to which a successful study guide for L2 speakers of English should adhere. In the research conducted for this study, a number of linguistic criteria for effective study guides were identified. These criteria were extracted from literature on effective writing/teaching in general, then discussed briefly in terms of their relevance for the specific purpose of writing effective study guides. Finally, these criteria were applied to critically evaluate the language used in three study guides used at a DLI.
\end{abstract}

Keywords: effective language, distance learning institution, linguistic criteria, academic culture, non-academic culture

\section{Introduction}

Culture is a complex concept but it can be defined as "the collective programming of the mind that distinguishes the members of one group or category of people from others" (Hofstede, Hofstede and Minkov 2010:6). Culture is made up of public symbols, and even smaller groups such as the academic culture have methods of socialisation, norms, values and social practices (Atkinson 2004:286). Many groups form cultural systems. In some cases, people have a common worldview or lifestyle because of a shared history or geography that helps to create and reinforce a cultural system. To create a culture, a group must first define itself as a group, 
which may be on the basis of nationality, ethnicity, gender, physical ability or disability, profession, geography, etc. Cultural identity is thus created when membership in one or more groups is claimed by an individual or by group members (Collier, in Samovar and Porter 2003:417-419; Guirdham 1999:61).

Holliday (1994:29-30) discusses the different sizes and levels of interacting cultures, from the culture of individual classrooms to national culture and the partially overlapping relations among them. For example, student culture would have both its own norms and practices which may overlap with national cultural norms and practices. Also, student culture may overlap with the norms and practices of youth culture which would partially overlap with those of national culture. Likewise, the professional academic culture of lecturers in a particular situation would partly overlap with national culture but would also in part be shared by other lecturers in other cultures in other parts of the world (Atkinson 2004:286).

In a tertiary institution, the lecturers have cultural capital as they set the minimum requirement of relevant content and discourse expertise. They make the rules while the students must get to know and obey these rules (Johns 1990:212-213). In contrast, the members of the non-academic culture have less cultural capital and are expected to meet the requirement of relevant content and discourse expertise (Bourdieu and Wacquant 1992).

\section{The need for effective language in study guides at DLIs}

The study guide remains the practical choice for teaching at a distance learning institution (DLI) in spite of the development and incorporation of various technologies (Unisa 2008:3). The aim of the study guide is to guide the students in the study of the course content sources, i.e. the textbooks (Kember 1991:13, Hyland 2009:112-113). The study guide therefore may be the only means of "communicating" with the lecturer and is in most cases the primary and sometimes the only teaching tool. Hyland (2009:112) believes that instructional texts such as study guides can help convey the values and ideologies of a particular academic culture.

The traditional DLI has diverse learners, such as older students, people seeking to improve their job skills, people who do not necessarily meet the requirements for study at a university, as well as first-generation students. At a DLI, there is also little or no social interaction between the student and lecturer, and as a result the student may feel isolated which could lead to him/her dropping out (Qakisa-Makoe 2005:55).

Sonnekus, Louw and Wilson (2006:50) allude to the fact that the level of exposure to technology may also differ among students. Furthermore, only a small percentage of students study in English as their first language (L1). According to Crosling (1983, cited in Erben and Fagan 1995:58), these students are even further removed from the academic culture when this language is the medium of instruction. For this reason, distance learning materials must be reader-friendly and accessible. Effective study guides have to fulfil the criteria for effective writing as well as effective teaching. As such, the formal, academic style of writing may not be effective in study guides.

In study guides, the writers are confined to the boundaries of the text. Speakers, however, may express ideas in several ways by making use of gestures, facial expressions and body language, according to Rowntree (1981:165-166). When speakers speak, they have the liberty of 
repetition, detailed explanations and using many examples to emphasise or explain a point. In written text, the writer has to be as brief as possible owing to space constraints. The flexible grammar and syntax of the spoken language allow the speaker to convey different meanings, and the listener has the liberty to ask for clarification or more examples. In written text, however, the grammar and syntax is not as flexible, and the reader cannot interrogate print and ask for feedback.

The academic culture is a typical discourse community (Atkinson 2004:286). Within the academic community there are various academic disciplines, and for this reason one could say that there are different discourse communities within the academic culture (Abdi, Rizi and Tavakoli 2010:1669-1670, Hyland 2009:59-61). For example, authors from the hard sciences may view their role differently from authors in the soft sciences, such as the humanities and social sciences. An author of the hard sciences, for example, may leave it to the methods, problems and findings in the discipline in order to allow the readers to draw their own conclusions. On the other hand, an author of the humanities and social sciences, for example, may identify strongly with a particular argument and try to persuade the reader to adopt his/her perspective. As a result, authors of the humanities and social sciences are far more involved and may use personal references more than authors of the hard sciences (Hyland 2005:181, 186187). Writers of the humanities and social sciences may want to persuade their readers more, while writers of the hard sciences expect their readers to have considerable knowledge of the subject, the specialised methods, instruments, materials and models in order to draw their own conclusions (Hyland 2005:184, Hyland 2009:61, 63). It therefore seems that writers in different disciplines represent themselves, their work and their readers in different ways.

Hyland (2009:113) states that writers borrow from the conventions, values and practices of their fields when they write instructional material, thereby representing their field in particular ways. The writers of study guides therefore have a responsibility to introduce the student to their academic culture in a friendly, non-intimidating way in accessible language. To do this, the writers of study guides at a DLI must be aware of the main characteristics of the students for whom they are writing in terms of educational background, age and the language(s) they speak. In this regard, some institutions provide information on students' backgrounds, languages and age, such as the University of South Africa's (Unisa) Department of Institutional Information and Analysis Portal (Unisa 2014).

\section{Research methodology}

The aim of the study reported in this article was to identify the linguistic criteria to which a successful study guide for second language (L2) speakers of English should adhere. With this in mind, I consulted academics who write study materials for postgraduate students at the DLI of a residential university. This DLI does not offer courses for first-year students, and these lecturers are experienced in writing materials for postgraduate students. The lecturers referred me to literature on writing which I examined in order to extract features for effective writing. This is core literature as it has been referred to by lecturers who are experts in the field of writing for distance education students. In addition, the authors of this literature are experts in the field of writing as they have produced many other publications in this field. From these features, I derived what I view as the essential criteria for effective writing. 
I obtained permission from the academics of a DLI to select three first-year study guides which I then evaluated on the basis of the identified linguistic criteria. I based my selection on seven study guides that were readily available to me and which lecturers agreed that I could examine for my research. The lecturers agreed that I could examine and report on the study guides on condition that I do not identify them (the authors of the study guides) or the titles of the study guides in my research report or article. The three study guides that I selected are introductory courses in communication, management and veterinary science. The study guides that I omitted are the more specialised and advanced modules. The three study guides that were evaluated are the following:

- Study Guide 1 from Arts and Culture: The topics of this study guide include an introduction to communication, different types of communication media, verbal and nonverbal messages, electronic communication and communication strategies.

- Study Guide 2 from Management: The topics of this study guide include public management, local government and municipalities, labour relations, elections, planning, structures, infrastructure and legislation.

- Study Guide 3 from Veterinary Science: The topics of this study guide include various animal diseases, toxicology and epidemiological methods.

These study guides were evaluated and analysed to determine how and to what extent the identified linguistic criteria are utilised in the study guides. Conclusions were drawn from the analysis and recommendations were made.

\section{The linguistic criteria for effective writing}

Eight linguistic criteria were derived from the literature, and are discussed briefly in the following sections.

\subsection{Appropriate use of contextualisation markers}

Contextualisation markers are meta-linguistic devices that help readers to interpret the text in a coherent, meaningful way. These devices show logical relations between ideas (Jung 2006:1929). Examples of contextualisation markers, according to Jung (2006:1931), include previews (e.g. There are four stages of this culture shock), topic shifters (e.g. Let's go back a minute), summarisers (e.g. To sum up so far), emphasis markers (e.g. Let me repeat it), exemplifiers (e.g. for instance), relators (e.g. goes along with that), definition markers (e.g. That's called), rhetorical questions (e.g. What is culture shock?), and logical connectives (e.g. first, second, and, or, well, all right, $O K$, and now).

Research has shown that a lack or misuse of contextualisation markers leads to poor comprehension or interpretation of messages. Mauranen (1993:254) found that readers who read a text with a large number of contextualisation markers comprehend the text more easily, and may subsequently experience a sense of authority. Contextualisation markers also make it easy to identify the logical connections in the text. According to Mauranen (1993:254), research revealed that lecturers who are L2 speakers of the language of instruction (English) could not convey intended logical relations among ideas owing to the lack or misuse of contextualisation markers. In follow-up research, the lecture of a L1 speaker of English was 
found to be well-organised and easy to follow owing specifically to the appropriate use of contextualisation markers.

\subsection{Appropriate paragraphing}

In written language, separate units of thought are visually represented by separate paragraphs. These (culturally affected) thought patterns affect paragraph structure. Usually the separate paragraphs are conveniently indicated by indentation or by the skipping of lines, even though this is, strictly speaking, not a necessity (Kaplan 1966:4).

According to the Sapir-Whorf hypothesis, there is a link between one's worldview and language (Kaplan 1966:3; see also Mandelbaum 1983 and Carroll 1956). The controversial claim of this hypothesis is that neither language nor culture can be understood without knowledge of the other, with the result that a person's view of the world may be determined by the structure of his/her language (Kaschula and Anthonissen 1995:17).

Languages differ in terms of thought patterns, and this is evident in the paragraph structure that visually represents thought patterns (Xing, Wang and Spencer 2008:73; Kaplan 1966:14). English, for example, has a linear thought pattern that develops a central idea to support, prove or argue something. In line with the deductive style of reasoning, the main idea is placed at the beginning of the paragraph followed by an explanation in the sentences that follow (Kaplan 1966:4-5, Connor 1996:30). The following is an example taken from Study Guide 2 of a paragraph with a linear thought pattern, where the first sentence is the main idea:

Land is a basic ingredient of economic development. A local government cannot develop economically if there is no land available. However, land for economic development is becoming scarce. As a result, governments must use smaller premises for such development.

Paragraphing can be useful to the reader only if the indicated paragraphs are genuine units of thought (Kaplan 1966:4). It is therefore important for writers to show the separate units of thought to the readers by means of paragraphing (Xing et al. 2008:73).

\subsection{The use of metatext}

Metatext refers to text about text (Enkvist 1990:15). According to Mauranen (1993:253), the use of metatext has a didactic function in that it guides, organises and clarifies, and reflects the writer's awareness about text as text (Mauranen 1993:253). The function of metatext is to describe the composition of the text but it does not contribute to the subject matter itself. A highly reflexive text, i.e. a text that contains a lot of text about text, can be characterised as personal, explicit and helpful. Metatext guides the readers, and makes them aware of the organisation, functional parts and central messages of the text (Hyland and Tse 2004:156). Hyland and Tse (2004:157-158) provide the following examples of metatext:

- In this section, we will discuss what classifications scholars have made in the past $[\ldots]$

- The organisation of the paper will be as follows: [...] 
Some readers may experience too much text about text as interfering, condescending, patronising and distracting (Mauranen 1993:254). However, I believe that in a DLI too much metatext is probably better than too little metatext as students have different needs and there is also an unequal relationship between the reader (student) and the writer (lecturer). In addition, the study guide must be accessible to as many of its target readers (the students) as possible.

\subsection{Explicitness}

Explicitness in text involves stating the main point of the text and other important facts explicitly and early on (Mauranen 1993:254, 256). From the Anglo-American point of view, this strategy makes the reader's task easier, and it is more likely that the reader will understand the message. This is in contrast to the Finnish strategy of explicitness, where the main point is placed at the end of the paragraph and the less important facts placed at the beginning.

If writers place the main points at the beginning of the text, it is like presenting the result and the most important elements at the beginning, and then giving an explanation of the result in the sentences that follow (Mauranen 1993:254, 256). This strategy makes the reader's task easier, and it is more likely that the reader will understand the message.

Explicitness in text is especially effective for readers (students) who do not necessarily know what the writer knows (Mauranen 1993:257). Explicitness can be used very meaningfully if readers come from a wide variety of cultural backgrounds. In a heterogeneous context, on the other hand, it becomes important and even necessary for the writer to be more explicit and not leave it to the readers to interpret the facts in their own way, as these interpretations could be very diverse and possibly inaccurate (Mauranen 1993:258). Also, if writers write for academics within a specialist field or discipline, they could assume that the target audience is homogenous, and then write in a less explicit way, as there is a shared knowledge and understanding between the writer and the readers (Mauranen 1993:258).

If the writer places important information towards the end of the text without explaining the information explicitly, the reader may have a more difficult task. When information is not explained explicitly, readers may have to make frequent inferences, and try and supply missing information from existing knowledge to fill in the gaps in the interpretation of the sentences until the end of the text has been reached (Mauranen 1993:257).

\subsection{Cohesion and coherence}

In their influential book entitled Cohesion in English, Halliday and Hasan (1976) distinguish between cohesion and coherence, noting that cohesion is a feature of a text while coherence is a feature of the reader's mental representation of a text, the idea being that cohesive texts lead to coherent mental representations (see also Halliday and Hasan 1989).

Johns (1986:251) says that coherence is text-based as well as reader-based, and that teachers should teach coherence by taking into account these two approaches. She explains that coherence is text-based as it "consists of the ordering and interlinking of propositions within a text by use of appropriate information structure (including cohesion)" (Johns 1986:251). However, coherence is also reader-based, as "the audience and the assignment must be consistently considered as the discourse is produced and revised" (Johns 1986:251). 
It has been shown that written texts which are high in cohesion are more easily comprehensible for students (see, for example, Ozuru, Dempsey and McNamara 2009). A written text should thus be more than "just a string of sentences" (Halliday and Hasan 1976:291) - although a text does consist of separate sentences, these sentences should be linked to each other in order for the text to form a meaningful whole. This cohesion is achieved by means of linguistic devices such as reference, substitution, ellipsis, conjunction and lexical cohesion (a taxonomy provided by Halliday and Hassan 1976). Reference involves words which signal to the reader whether a specific piece of information should be retrieved from the preceding text, from the text which follows or even from outside of the text (for example, from the situation or context - in the case of a study guide, the context could be the field on which the specific academic module focuses). Substitution refers to substituting a more general word/phrase with a more specific word/phrase (which avoids repetition and again links pieces of information to each other). Ellipsis involves omitting a word/phrase when this word/phrase can be left implicit without detracting from the meaning of a clause/sentence (Halliday and Hasan 1976:291). These three cohesive devices are illustrated by the following sequence of sentences:

I love my new laptop. This is the best one I have ever had. Mine is black while John's is grey.

In the above example, this refers back to my new laptop (reference), one refers to laptop (substitution) where laptop is omitted completely, and in the last sentence, Mine is a substitution for laptop.

\subsection{Guiding inferencing}

Inferencing involves the reader deducing or inferring meaning from the message of the text, and interpreting a text by adding information which is not overtly present. It can be likened to supplying the proverbial missing link. Inferencing depends on the knowledge of the writer and reader, as well as the context (Enkvist 1990:17).

Inferencing requires the writer and reader to share a picture of the relevant aspects of the world. The writer must manage inferencing properly by adapting the message to the knowledge, reading capacity and reading ability of the reader. The writer must estimate what the reader already knows and how good the reader is at discourse processing under the relevant circumstances. It is therefore important that the writer includes retrievable world knowledge in the text. When we interpret a text, we activate and draw on the relevant parts of our knowledge store to fill in the gaps in the actual chain of propositions (Enkvist 1990:17).

According to Enkvist (1990:20), a message is not interpreted in a vacuum; it triggers a process of interpretation. In this regard, the interpreter's previous knowledge plays a crucial role in how the message is interpreted (Enkvist 1990:21). Interpretation is thus determined not only by knowledge of the language but also by the extent of the reader's ability to retrieve relevant information from schemata, scripts and other organised deposits of knowledge. People can interpret a text when they can build a plausible text world around it. If the reader can build a world around a text, the text can be interpreted in many ways depending on the extent of the reader's own text world (Enkvist 1990:21). 
Enkvist (1990:22) suggests that writers provide examples of relatively neutral topics that one can assume the students are equally familiar with or that are at least part of the specific subject's curriculum. Specialist terms can also be introduced in a systematic manner by giving a definition, supplying background information, providing a synonym, describing a context, and then providing examples.

\subsection{Interpersonal style}

According to Halliday (1973:41), interpersonal style is the use of language to express social and personal relations to interact with readers. Connor (1996:18) says that writing involves more than a discursive process of generating, organising and translating ideas into text. Writing is regarded as an interaction within a particular discipline or scholarly community and is therefore viewed as interactive and social in nature. Hyland (2005:173) supports this idea by stating that written texts embody interactions between writers and readers.

Evidence of the use of interpersonal style in a text is when the pronouns $I$, we and you appear in the text (Ventola 1997:163). Words such as perhaps and may also belong to the category of words that serve the interpersonal function of language (Ventola 1997:157). The level of interactivity of academic texts differs: writers who prefer a more impersonal style will adopt a less interactive style, and writers who prefer a more interpersonal style will adopt a more interactive style (Duszak 1997:18).

A dialogic style in a text may also serve the interpersonal function of language. Duszak (1997:13) notes that writers who are sensitive to readers' needs may adopt a dialogic style, which is typical of Anglo-American texts. A writer who writes in a dialogic style gives more guidance, interacts with the readers, and writes reader-friendly texts that are more interpersonal in nature. This is in contrast to the impersonal style of German, Polish and Czech writers, for example, who generally use creative thinking to produce texts in the name of science and for the sake of truth, rather than writing for the reader's joy and benefit (Duszak 1997:13).

The assertiveness of writers varies between assertive (This is the case) and tentative (This may be the case) (Duszak 1997:13). The level of assertiveness in the text may also determine whether a text will be interpersonal or impersonal in nature. Writers who come across as being too assertive may give the impression that they are arrogant. Conversely, not being assertive enough may give the impression that the writer lacks confidence (Ventola 1997:176). Hyland (2005:176) maintains that writers use language to express their stance, i.e. as a way to convey their judgments, opinions and commitments, and also for engagement, thereby connecting with and acknowledging others.

The English system of modality allows writers to modify their messages. For example, when a statement is made, communicators can modify it on the basis of their assessment of its probability and frequency (Hyland 2005:178, Ventola 1997:161). Amongst other things, modal verbs, modal adverbs and particles, the use of certain personal pronouns and the avoidance of others, the use of agentless passives and other impersonal expressions can be used to modify statements that are assertive so that they come across as more tentative (Ventola 1997:163).

Hyland (2005:175) refers to the role of hedging and boosters as communicative strategies in texts for conveying reliability and strategically manipulating the strength of commitment to 
claims to achieve interpersonal goals. Lakoff (1972, cited in Kreutz and Harres 1997:182, 184) uses the term "hedging" when referring to the "fuzziness" of language in formal and informal speech, and also in academic writing. He states that hedges are words which make meanings fuzzier, and which indicate uncertainty and tentativeness. Hedges, also referred to as "modality markers", are devices like possible, might, and perhaps that indicate the writer's decision to withhold complete commitment to a proposition. For example, the phrase $(O)$ ur results suggest shows that the writer is more tentative in his approach (Hyland 2005:179). A possible explanation for the use of hedging is the need to interact with and include the reader in the process of writing and reading (Hyland 2005:179). It has the function of toning down, mitigation and politeness, and the extent to which hedging is used may indicate whether or not writers are reader-centred (Kreutz and Harres 1997:184).

Boosters, on the other hand, are words like clearly and obviously which allow writers to express their certainty in what they say and to mark involvement with the topic. Hyland (2005:179) provides the examples "static images surely cannot trigger our capacity [...]" and "(w)ith a few interesting exceptions we obviously do not see a static image as moving". Hyland (2005:187188 ) found that writers use hedges far more in the soft sciences, such as the humanities and social sciences, than in the hard sciences (see section 2).

\subsection{Simplicity}

A measure of simplicity is the lexical density of a text, i.e. a measure of the amount of information in a text (Ventola 1996:154, 160-161). In order to reduce the lexical density of texts, writers are advised to write in short, clear sentences (Ventola 1996:154, Lewis and Paine 1985:56). They are also told to avoid the use of heavily complex constructions, nominalisations and the overuse of technical terms (Ventola 1996:155). Different ways to measure readability have been developed throughout the years. One of the ways involves using the Fog Index to measure the "fogginess" or heaviness of a text by judging its average length of sentences and the proportion of multi-syllabled words that it contains (Rowntree 1990:230). The Fog Index gives a fair indication of the density of texts.

However, writers also receive the opposite advice, namely to write in a more complex, scientific way, and to use an impersonal, formal tone (Ventola 1996:155). Such conflicting pieces of advice sometimes leave writers confused. If a writer's text is too simple or too complex, the text will be less appreciated by the readers than a text that is well-balanced in terms of language and content (Ventola 1996:156). For this reason, a writer should be aware of the various linguistic choices that can be made, and their effects on the text (Ventola 1996:157).

\section{Data analysis: Assessing the study guides in terms of the criteria}

Table 1 summarises the linguistic criteria discussed in sections 4.1 to 4.8 , and indicates how the three study guides were assessed in terms of each of the criteria. 
Table 1. The linguistic criteria and associated questions for the evaluation of the study guides

\begin{tabular}{|c|c|}
\hline $\begin{array}{l}\text { Linguistic } \\
\text { criterion }\end{array}$ & Questions asked to assess study guide in terms of criterion \\
\hline $\begin{array}{c}\text { Contextualisation } \\
\text { markers }\end{array}$ & $\begin{array}{l}\text { Does the text make use of contextualisation markers } \\
\text { - to a sufficient degree? } \\
\text { - in a way that makes logical relations between different concepts, ideas } \\
\text { and statements clear? } \\
\text { - in a way that makes the text more reader-friendly and easier to follow? } \\
\text { - Are contextualisation markers used to a similar degree throughout the } \\
\text { study guide or are they missing from substantial sections of the text? }\end{array}$ \\
\hline Paragraphing & $\begin{array}{l}\text { - Do paragraph breaks indicate separate units of thought? } \\
\text { - Do the writer's paragraphs indicate genuine units of thought in the text? } \\
\text { - Do paragraphs follow a linear thought pattern, i.e. do paragraphs have } \\
\text { a topic statement followed by sentences that explain the statement? }\end{array}$ \\
\hline $\begin{array}{l}\text { The use of } \\
\text { metatext }\end{array}$ & $\begin{array}{l}\text { - Does the writer give guidelines on the organisation of the text? } \\
\text { - In doing so, does the writer make the content explicit? } \\
\text { - Are the guidelines clear? }\end{array}$ \\
\hline Explicitness & $\begin{array}{l}\text { - Are the main points and important information stated early in the } \\
\text { different sections? } \\
\text { - Is the important information easily identifiable? } \\
\text { - Does the writer use strong action verbs? }\end{array}$ \\
\hline $\begin{array}{l}\text { Cohesion and } \\
\text { coherence }\end{array}$ & $\begin{array}{l}\text { - Are there explicit links between ideas in the content of the study guide? } \\
\text { - Does the text make use of cohesive devices (such as references, } \\
\text { substitution, ellipsis, conjunctions and lexical cohesion) to make the } \\
\text { links between separate ideas clear/explicit? } \\
\text { - Are the examples used in the study guide relatively neutral in terms of } \\
\text { geographical location, cultural group, politics and religion, and how } \\
\text { likely is it that the student will be able to relate to them? } \\
\text { - Do the sections of text in general contain all the pieces of information } \\
\text { that are necessary for the student to understand the message? }\end{array}$ \\
\hline $\begin{array}{l}\text { Guiding } \\
\text { inferencing }\end{array}$ & $\begin{array}{l}\text { - Are the items, sentence constructions and examples in the text } \\
\text { appropriate for the level of study (i.e. first-year level)? } \\
\text { - Are the specialist terms essential for the comprehension of new } \\
\text { concepts? } \\
\text { - Are new terms explained carefully when they are introduced? } \\
\text { - Does the writer remind students of the new specialist terms that have } \\
\text { been introduced? } \\
\text { - Is the number of new terms appropriate for the level of study (i.e. } \\
\text { first-year level)? } \\
\text { - Does the writer use the newly introduced terms consistently? } \\
\text { - Are the vocabulary and sentence construction precise? }\end{array}$ \\
\hline
\end{tabular}




\begin{tabular}{|c|c|}
\hline $\begin{array}{l}\text { Interpersonal } \\
\text { style }\end{array}$ & $\begin{array}{l}\text { - Does the writer interact with the student? } \\
\text { - Is the writer tentative in his approach? } \\
\text { - Does the writer sound authoritative but not overassertive? } \\
\text { - How often does the writer use modality such as modal verbs and } \\
\text { modal adverbs (e.g. may, perhaps)? } \\
\text { - Does the writer invite the reader to take part in an activity or does the } \\
\text { text contain instructions only? } \\
\text { - Does the writer make use of personal references (I, we, you)? } \\
\text { - Are the personal references unambiguous, i.e. is it clear who the } \\
\text { writer is referring to? } \\
\text { - Does the writer use contractions (e.g. I'm instead of I am, don't } \\
\text { instead of do not)? }\end{array}$ \\
\hline Simplicity & $\begin{array}{l}\text { - Does the writer vary the length of sentences? } \\
\text { - Does the text contain some simple verb forms and not too many } \\
\text { nominalisations? } \\
\text { - Does the text contain some simple words (three syllables or less)? }\end{array}$ \\
\hline
\end{tabular}

In the following sections, I will present a comparison of the three study guides on the basis of how they adhere to the linguistic criteria. I would like to emphasise, though, that my evaluations of these study guides are not based solely on the two or three examples provided for each linguistic criterion; instead, the examples that are provide were chosen as representative of the study guide's language use in general. I believe that my judgement of the study guides for each criterion was an informed one, based on experience gained by having worked for twelve years in the capacity of language coordinator for study material.

\subsection{Appropriate use of contextualisation markers}

\subsubsection{Study Guide 1}

Very few contextualisation markers were found in this study guide. Although the absence of these markers does not seem to detract from the coherence of the text in any obvious way, I presume that it would require more concentration from the student, especially a first-year student, to interpret the various sections of the text as a coherent whole. By not using contextualisation markers, the writer places the responsibility on the (first-year) student to infer the logical relations between different concepts, ideas, statements and sentences (see section 4.1). The following are two examples from the text that show how the absence of contextualisation markers makes a paragraph seem like a list of unrelated sentences rather than a coherent whole:

(1) People often rely on the radio to be their companion owing to their circumstances. Radio stations broadcast programmes in which the public can participate. Radio stations provide opportunity [sic] to include all members of the community. South Africans living overseas listen to their favourite radio station via the internet or by means of satellite radio.

(2) Louw and Visser's greatest concern was the transmission of messages from communicator to recipient. The clarity of the information is an important issue. Louw 
and Visser did not consider the content and meaning of the message. Louw and Visser's model is referred to as the technical model.

\subsubsection{Study Guide 2}

The writer of this study guide uses contextualisation markers adequately. In instances where he uses them, it could lead to a more coherent interpretation of the text. The following sections of text illustrate ${ }^{1}$ :

(3) These large amalgamated local government areas experience great disadvantages from the point of view of local government. First, the activities of personnel are more complicated and this leads to confusion. Second, it makes the coordinating roles of politicians more difficult. As a result, the resident representatives have less influence over the management of local services, and, ultimately, local residents have less input into local government.

(4) As politicians, councillors are forever involved in resolving conflict between people. Because people have differing views, they have different interests too. Therefore, conflicts of interest are common. These conflicts have to be resolved to maintain social order.

\subsubsection{Study Guide 3}

The use of contextualisation markers makes the text easier to follow. In a highly technical subject, such as veterinary science, it is essential that writers use these markers to make the text reader-friendly and easy to follow. The use of contextualisation markers in Study Guide 3 is illustrated by the following examples:

(5) Dairy cows are very expensive, and farmers would be very angry if a cow is slaughtered that is actually negative for the disease. Therefore, if cows in a herd are found to be positive on the screening test, the herd is retested using other tests.

(6) You cannot calculate the period prevalence rate as no period is specified in the problem. However, the prevalence calculated will be the period prevalence rate as the problem mentions consulting retrospective records, which presumably covered a few months or years.

\subsection{Appropriate use of paragraphing}

\subsubsection{Study Guide 1}

In Study Guide 1, the writer indicates genuine units of thought by means of separate paragraphs. In some cases, the paragraphs do seem a bit long but even these long paragraphs indicate what are, strictly speaking, single units of thought. In most cases, the writer places the main point at the beginning of the paragraph and explains this point with supporting evidence in the sentences that follow. This is known as the linear style of paragraphing (see section 4.2), and represents a deductive style of reasoning, as illustrated by the examples in (7) and (8):

\footnotetext{
${ }^{1}$ Note that the italicisation of items in these examples and those to follow is my own.
} 
(7) Electrically powered calculating machines paved the way for computers. Computers were initially used to perform lengthy calculations, and the personal computer only became a household commodity in the 1980s. Now personal computers have become known as multimedia PCs because various media, such as videos, CDs, images, telephones and cameras can be integrated to enhance the distribution of information.

(8) Tourism is of particular importance to the country. All the provinces have tourist attractions. In addition, each province has its own logo. The various logos of the provinces have symbolised different meanings.

\subsubsection{Study Guide 2}

In some instances in this study guide, the paragraphing is confusing, but in most instances the writer follows a linear pattern by using deductive reasoning. Take note of the linear pattern in the following paragraphs:

(9) Once a new local government has been created, it exists on paper only. The paper creation becomes a local government only once people are included, and this happens by means of elections. After the first election for a new local government, elections must be held at least every five years. However, before elections can be held, the local area must be divided into wards and a voter's roll compiled.

(10) Local government areas are characterised by a heterogeneous population. Although this population has the same system of local government for a certain area, the citizens represent a variety of unique cultural values, which can differ from one area to the next. This leads to a significant difference in the inputs that the various local governments receive.

\subsubsection{Study Guide 3}

The writer of this study guide makes use of the linear style of paragraphing, as shown in the following examples:

(11) In many diseases it is hard to tell if the animal or human is sick. Sometimes people or animals can be sick and not even be positive on tests. For instance, in the early stages of HIV infection, the blood test can be negative for antibodies so that you would think the person has not got the disease.

(12) Toxigenicity is the ability to produce toxins. However, some toxins excrete other dangerous toxins. These toxins cause bloody conditions such as bloody diarrhoea and kidney failure. If untreated, this could result in death. 


\subsection{The use of metatext}

\subsubsection{Study Guide 1}

The writer of this study guide makes use of metatext to guide the student through the text, as illustrated by the following examples:

(13) This chapter guides you through the various stages of the communication act.

(14) In chapter 7 of the study guide you will find a discussion of the specific communication strategies.

(15) In study unit 2 we looked at the development of communication. At the end of the study unit we touched on verbal and nonverbal communication. We will elaborate on these concepts in the next unit.

\subsubsection{Study Guide 2}

In Study Guide 2, there is some evidence of metatext which serves to orient the reader to the structure and content of the study guide. However, in my opinion, metatext is not used adequately throughout this study guide. The following is a (rare) instance where the writer uses metatext:

(16) In this chapter, a discussion on local government in South Africa, it is important to explain the most general terms [...] The aim of this chapter is therefore to define terminological concepts.

\subsubsection{Study Guide 3}

The writer uses text reflexivity to guide the reader through the text. The following are examples of metatext as used in this study guide:

(17) In the next unit, all the characteristics of the host population will be given in detail.

(18) In the previous unit, we briefly defined health and discussed the difficulties involved in identifying diseases. In this unit we will look closely at the transmission of diseases.

\subsection{Explicitness}

\subsubsection{Study Guide 1}

The writer of Study Guide 1 succeeds in placing the main point in each section early on in the text. For example, in the chapter entitled "The communication process" he starts off with an explanation of the term "communication" and the communication process, then expands with examples, and elaborates on the term "communication process". The same applies to the chapter entitled "Language and communication" - immediately, the writer starts writing about language in communication. In the subsequent sentences, he provides examples and expands on the main point by providing information on language and thought, and how the relationship between the two plays a role in communication. 
Additionally, the writer uses strong, precise action verbs, for example:

List at least two words that describe communication.

(20) Compare the three situations.

(21) Find three examples of the communicative functions of language.

\subsubsection{Study Guide 2}

In most instances, the writer of Study Guide 2 does not start the sections of text with the main idea. For example, in the section entitled "Local government structures", he first provides definitions of "local government", and then explains concepts such as 'municipality' and 'democracy' before mentioning the local government structures which, to my mind, should be mentioned much earlier, given the title of the section. In using this long-winded way to get to the most important information, the main point is not made explicit. Only after four pages does the writer finally get to the most important information.

\subsubsection{Study Guide 3}

This writer generally places important information early on in the various sections of text. For example, in a section entitled "Epidemiological methods", he introduces the methods - e.g. monitoring, surveillance and questionnaires - in the first few paragraphs, and then proceeds to expand on each concept. Similarly, in a chapter which deals with the nature, causes and transmission of animal diseases, the writer starts by explaining the concepts referred to in the chapter's title. Then he gives a case history that expands on the nature, causes and transmission of animal diseases. Throughout the chapter, the writer provides more examples and expands on the topic. In another instance, in a section dealing with the epidemiological triad, he first explains what this is, then distinguishes between its three components, and finally explains the different factors involved in each of the three components.

\subsection{Cohesion and coherence}

\subsubsection{Study Guide 1}

Even though this writer does not extensively make use of cohesive links between sentences and ideas, he creates coherence by keeping sentences simple and short, and providing examples that serve to build a plausible text world for the students. In addition, the writer structures the paragraphs according to the linear style, and uses the deductive style of reasoning by placing the main point at the beginning of the paragraph and explaining this point in the subsequent sentences. He also introduces new terms in a systematic manner, and explains new information by sketching scenarios and providing relevant examples. For example, the writer defines the term "hypothesis" as "a testable statement that contains a cause-and-effect relationship", and provides the following relevant example:

(22) If you do not hand in your assignment, then you will not be admitted to the examination. 


\subsubsection{Study Guide 2}

The writer of Study Guide 2 generally uses long sentences, which may hamper the coherent interpretation of a text. When a reader (student) cannot build a consistent world view around a text, the text may be incoherent for him/her. However, overt links in the text could contribute to its coherent interpretation (see section 4.5). The following are examples of long sentences which hamper a coherent interpretation of the text and place unnecessary processing demands on the students:

(23) If a municipal council is dissolved or does not have enough members to form a quorum for a meeting, the MEC for local government in the province must appoint one or more administrators to ensure the continued functioning of the municipality until a new municipal council is elected or until the council has sufficient members to form a quorum.

(24) An executive mayor is entitled to receive reports from committees of the municipal council and to forward these reports together with a recommendation to the council when the matter cannot be settled by the executive mayor in terms of the executive mayor's delegated powers.

In spite of the long sentences, the writer generally avoids the use of the passive voice form, which contributes to the coherence of the text. The following are examples of shorter sentences where the writer uses the active voice form:

(25) Local governments with a reasonable number of officials divide their personnel into different departments.

(26) Departmental heads play an important role in the personnel function.

(27) This law provides criteria and procedures for the determination of municipal boundaries.

\subsubsection{Study Guide 3}

This writer provides definitions, and then lifts key points out of the definition and discusses them. He also adds to coherence by providing appropriate examples, illustrated by the following:

(28) The risk of disease in animals is closely related to where they live and their habits. For example, rabies occurs mainly in kudu, which are browsers rather that other types of antelope that are chiefly grazers, in areas where saliva is spread on the branches and thorns of bushes by infected kudu.

(29) It is far more difficult to define disease than health. For instance, a cow with a positive test for brucellosis may look healthy, yet she can transmit the disease to other cows through her milk.

(30) Indirect transmission of disease through mechanical means is very important for AHTs. For instance, you can transmit foot-and-mouth disease by driving a car from an area where the disease is present to another. 


\subsection{Guiding inferencing}

\subsubsection{Study Guide 1}

The writer of Study Guide 1 uses relevant examples as far as possible. He explains the term "nonverbal communication" by using the following relevant example:

(31) If you deliberately make eye contact with somebody you are attracted to, it is an example of nonverbal communication.

Further, he explains external barriers to communication through the following example:

(32) While you are listening to your lecturer, external barriers may prevent you from listening, such as students screaming outside, your fellow student's cellphone ringing and a window slamming.

At one stage the writer uses a Madam and Eve cartoon to explain the concept of 'verbal communication'. Madam and Eve is a South African cartoon which first-year students would probably have come across in magazines and/or on the television, hence it is something with which they can identify.

The writer does not use many technical terms but when new terms are introduced, it is done in a systematic manner (see section 4.6). This can be illustrated by the way he introduces the terms "telecommuting" and "intentional communication". In introducing the term "telecommuting", the writer gives the synonym "distance working" in brackets. He supplies the definition "telecommuting refers to the enjoyment of flexibility", and provides some background information:

(33) The first experiments in this field began in 1973. It was only in the 1980s that employees began to work from their "home offices" on desktop computers provided by their employees.

Finally, the writer also describes a context and/or examples:

(34) Today, telecommuters carry notebooks or laptops and are linked or connected to the office via their company network and other communication channels.

\subsubsection{Study Guide 2}

The writer of Study Guide 2 does not introduce new terms in a systematic or effective way. For example, to introduce the term "democratisation", he simply explains that a democratic state is "a state where the citizens of the state elect all governments in the state". He does not explain the term "democratisation" itself, and he does not elucidate the link between a "democratic state" and "democratisation". In this case, the student has to infer the meaning of the term from the definition of a related term, which could be a daunting task for a first-year student. Also, the writer defines the term "transformation" as "the change in outward experience or inner character of something" and then relates it to local government, saying that "transformation of 
local government is changing one or more of all aspects of local government". However, nowhere else in the study guide does he use the term again.

Furthermore, this writer does not provide examples that the student can relate to; in fact, he very rarely provides examples. He just explains terms without relating them to the experiences of the students. For example, he does not probe the student to think about the local government in his/her community. Under the heading "Income from local sources", one would expect that the writer would explain precisely what the heading states. However, in one instance he makes the following statement:

(35) Most of the ministries of the central government participate in the control function over local government. For example, the Minister of Health will ensure that local government deals with public health matters according to the central government's public health policy.

In this example, he introduces additional concepts (such as 'central government' and 'public health policy') which, to my mind, need their own explanations. The writer also does not offer an explanation of the term "local sources"; instead, he refers to the situation in Nigeria, and, in the process, uses the word "demarcation" without explaining the meaning of this term. I am sure many (first-year) students would need to consult a dictionary when they encounter this term. In this case, the writer places the burden of inferencing on the student.

In most cases, the writer uses specialist vocabulary without providing definitions; there are, for example, no definitions of the terms "constitutions", "amenities", "councillor", "resolution", or "statutory control". The following examples illustrate how the writer sometimes uses words and sentences that could have been expressed in simpler terms:

(36) An unrehabilitated insolvent is disqualified from becoming or remaining a member of the board.

(37) The demarcation and alteration of boundaries, amalgamation of different areas, and the reduction and extension of the rights of local government are all important matters.

The writer uses terms such as "require" instead of need, "acquires" instead of gets, "allocate" instead of give, and the nominalisation "functional effectiveness" instead of the simple verb functions. Such unnecessary nominalisation is also used when he states that "The participation of voters is essential" instead of All voters must participate.

\subsubsection{Study Guide 3}

This writer frequently provides examples, although these examples assume that the students possess some background knowledge. The student may or may not have the necessary background knowledge to which the following examples refer:

(38) The risk of disease in animals is closely related to where they live and their habits. For example, rabies occurs mainly in kudu, which are browsers. 
(39) Many animals with this disease never recover fully. For instance, a cow with a positive serological test for brucellosis must be treated regularly.

In Study Guide 3, the writer also provides definitions and explanations, and then discusses and explains key terms appearing in the definition in order to facilitate a coherent understanding of the text. The following examples illustrate:

(40) Veterinarians do an epidemiological investigation. An epidemiological investigation is a clinical investigation, which is a systematic approach to the observation and recording of clinical signs.

(41) The diseases have an incubation period. The incubation period is the period of time between the initial exposure and the appearance of symptoms.

The writer introduces specialist terms by providing definitions followed by examples and referring to terms which are related or stand in contrast to the term under discussion. For example, when he explains "primary determinants", the writer gives a definition ("factors which have a major effect in disease"), provides some examples, and then contrasts the term with "secondary determinants".

\subsection{The use of interpersonal style}

\subsubsection{Study Guide 1}

In Study Guide 1, the writer mainly uses the interpersonal, interactive style, as in the examples below.

(42) The purpose of the activities is to assist you with the content.

(43) Try to determine the role of television in your household.

(44) Consider the role that newspapers play in your community.

The writer modifies statements throughout the text through the use of modal verbs and adverbs, which allows the reader to reflect on and evaluate some of the facts (see section 4.7). The following are some examples:

(45) Your definition will probably be something like the one in the example.

(46) Your example of verbal communication may include a conversation with a friend.

(47) This is perhaps the most important function of communication.

\subsubsection{Study Guide 2}

The writer of Study Guide 2 comes across as overassertive in many instances, owing to the lack of modality markers and hedging (see section 4.7). He does not often use an interpersonal style. 
By not addressing the reader (student) directly, the writer gives the impression that the text is purely an academic text. See the following examples:

(48) Like any other sphere of government in South Africa, local government has not been able to escape the impact of transformation.

(49) Local government authority lies in its legal ability to create by-laws and to implement them in order to perform its functions.

\subsubsection{Study Guide 3}

Study Guide 3 is characterised by an interpersonal, interactive style. Even though the content is of a scientific and technical nature, the writer uses the dialogic style effectively, as illustrated in the following examples:

(50) I recently saw this report in a newspaper. [...] You may also have seen reports like these.

(51) Your practical experience in the workplace will help you to achieve these outcomes.

This writer includes the reader in his style of writing, and shows that he is reader-oriented. In the following instances, he effectively shifts between the factual presentation of information and the use of the dialogic style through which he addresses the student directly:

(52) Recently avian influenza has caused disease and deaths in people who have worked with infected chickens. As an AHT, you have a major role to play in the prevention of such diseases.

(53) The collection and recording of data are important. You can build the finest and most expensive mansion, but it will fall down if the foundations are faulty.

(54) Clinical signs are effects of disease that can be observed by others, or detected by measuring clinical parameters such as fever and heart rate. Examples of clinical signs that you, as an AHT, may observe are the nervous signs associated with heartwater in sheep and bloating due to indigestion.

This dialogic style breaks the monotony, and gives the reader (student) an opportunity to reflect on, absorb and apply the information.

Where possible, the writer also modifies his statements by using modal verbs and adverbs. The following examples illustrate this:

(55) Perhaps the most difficult part was dividing the data into groups.

(56) Probably the most important thing about the information in the field is that it must be accurate.

(57) If you sampled the entire population, you might get many more dairy cows than beef cows. 


\subsection{Simplicity}

\subsubsection{Study Guide 1}

In Study Guide 1, the sentences are generally short, which enables the writer to keep the lexical density of the text quite low (see section 4.8). The following examples illustrate this:

(58) We can therefore say that one of the reasons for the proliferation of definitions is that there is no single approach to communication. Definitions differ according to the theorist's views about communication. In this section we will highlight the various views on communication.

(59) Communication takes place in many contexts. We communicate with people that we know well and with people that we are not familiar with. We use many communication strategies to communicate.

\subsubsection{Study Guide 2}

In the following instances, the frequent occurrence of long sentences increases the lexical density of the text in Study Guide 2:

(60) In areas where a large number of interest groups, sometimes with conflicting and overlapping objectives, are active and confuse the community, political parties play an important role in arranging objectives for presentation to the residents and this makes it easier for the residents to make a choice.

(61) Although such representatives receive power from the community, which they can impose on the community through persuasion, legislation, and even coercion, it is important to remember that the elected representatives remain responsible and accountable to the electorate for the way in which they use the power received in trust from the community.

\subsubsection{Study Guide 3}

Owing to the highly scientific, technical nature of the text, the writer of Study Guide 3 had to use complex words, such as "fluctuations", "epidemic" and "carcasses". The fact that he mostly makes use of short sentences, however, reduces the lexical density of the text and makes inferencing easier. This is illustrated by the examples below:

(62) Some of these variables are also linked to each other. For instance, in the case history the climate was linked to the number of colloids and the age of the horses was linked to their immune status. These sorts of links between variables are known as associations.

(63) The vector merely moves the infective material from the infected animal to the host. During the process there is no change in the number or form of the organisms present. A good example of a mechanical vector is the common housefly. 
(64) It is obvious that poor housing provides opportunities for disease. Good management and husbandry also provide optimal nutrition of animals and promote the welfare of animals. Fencing and paddocks can also prevent contact between carrier animals and susceptible hosts.

\subsection{Summary of the results}

Table 2 below provides a summary of the judgements made for each study guide in terms of the linguistic criteria. Each judgement is presented as an option on a Likert scale, where good $=3$, adequate $=2$, inadequate $=1$, and poor $=0$.

The options on any Likert scale are inevitably arbitrary, to a greater or lesser degree. However, making use of such a scale allows one to at least get an indication of the extent to which each study guide meets the criteria for effective writing/teaching, and allows one to compare the study guides with each other.

Table 2. Summary of the evaluation of the three study guides in terms of the linguistic criteria

\begin{tabular}{|l|l|l|l|}
\hline Linguistic criterion & Study Guide 1 & Study Guide 2 & Study Guide 3 \\
\hline $\begin{array}{l}\text { Appropriate use of } \\
\text { contextualisation markers }\end{array}$ & $0=$ Poor & $2=$ Adequate & $2=$ Adequate \\
\hline Appropriate paragraphing & $3=$ Good & $2=$ Adequate & $3=$ Good \\
\hline The use of metatext & $2=$ Adequate & $1=$ Inadequate & $3=$ Good \\
\hline Explicitness & $3=$ Good & $0=$ Poor & $3=$ Good \\
\hline Cohesion and coherence & $2=$ Adequate & $2=$ Adequate & $2=$ Adequate \\
\hline Guiding inferencing & $3=$ Good & $0=$ Poor & $2=$ Adequate \\
\hline Interpersonal style & $2=$ Adequate & $0=$ Poor & $3=$ Good \\
\hline Simplicity & $3=$ Good & $0=$ Poor & $2=$ Adequate \\
\hline \multicolumn{1}{|c|}{ Overall score: $/ \mathbf{2 4}$} & $\mathbf{1 8}$ & $\mathbf{7}$ & $\mathbf{2 0}$ \\
\hline
\end{tabular}

From this tabulated summary, it is clear that Study Guide 2 ranks lowest in terms of effective writing/teaching, with an overall score of 7 out of 24, while Study Guide 3 ranks highest with an overall score of 20 out of 24. Study Guide 2, with an overall score of 7 out of 24, receives the ratings "poor" and "inadequate" for five of the eight criteria (four "poor" ratings and one "inadequate" rating), whereas Study Guide 3 - with an overall score of 20 out of 24 - receives the ratings "good" and "adequate" for all eight criteria (four "adequate" and four "good"). Study Guide 1 receives the rating "adequate" for three criteria, the rating "good" for an additional four criteria, and the rating "poor" for only one criterion, namely "appropriate use of contextualisation markers". From this it follows that both Study Guides 1 and 3 exemplify effective writing/teaching.

\section{Limitations of the study}

The research reported in this article has two main limitations (see Vergie 2010). Firstly, it might have been more informative to compare two or three study guides used for modules offered by the same faculty or even for modules that form part of a single subject, as this would have made 
the study guides more comparable. Secondly, the way in which the study guides were evaluated in terms of the linguistic criteria could have been made more systematic by deciding exactly how to evaluate a study guide on each criterion. For example, if a writer sometimes makes use of metatext and sometimes not, how does one evaluate the study guide in terms of the linguistic criterion "use of metatext"? Frequency counts converted into percentages might allow one to make a more informed judgement of a study guide in terms of each criterion. In addition, it is very likely that the eight linguistic criteria do not contribute equally to how effective (the language used in) a study guide is, and that some of the criteria are more important than others and should thus be weighted differently in an overall judgement of a study guide.

Although the scope of this study is limited, I believe that the aim of this study was achieved by managing to identify the linguistic criteria for a successful study guide for DLI students who are L2 speakers of English.

\section{Implications of the research findings}

The results of the research reported in this article can be of practical use to writers of study guides. In light of the research results, I have the following three general recommendations with regard to study guide writing:

a. Writers must learn to be more reader-oriented, i.e. they should strive to keep the reader in mind when they communicate in writing. For this reason, writers should be made aware of the main characteristics of the students for whom they are writing (in terms of, for example, educational background, age and language proficiency).

b. Writers should keep the linguistic criteria for effective study guides in mind while writing study guides as well as for other types of written communication with their students (e.g. tutorial letters).

c. Staff development departments in universities should offer writing courses for their lecturers where these linguistic criteria can be introduced and practised.

In view of recommendation (b) above, I have set up a list of 25 "do's and don'ts", which can be used by study guide writers as a type of checklist (Vergie 2010):

1. Use contextualisation markers to show logical relations between ideas and sentences, introduce content, change the topic, summarise a chunk of content, emphasise certain sections and ideas, link different pieces of information, stimulate the student through the use of rhetorical questions, and connect sections of related information.

2. Make the thought structure visual to students by indicating separate units of thought via appropriate paragraphing.

3. Ensure that paragraphs follow a linear thought pattern by stating the main point first, followed by examples and illustrations to explain this point.

4. Ensure that paragraphs are not too long or too short; in other words, use thought breaks appropriately.

5. Use text about text to organise the text and to provide guidelines for the student about the structure of the text. However, take care not to come across as patronising. 
6. Let the students "hear" your voice.

7. Explicitly state the main point and other important information early on in the text, especially when writing for a heterogeneous group.

8. Use strong action words such as notice, reflect and write to increase the explicitness of the information you wish to communicate.

9. Avoid the use of the passive form as this makes the content less explicit.

10. Create explicit links between ideas in the content of the study guide by means of cohesive devices such as references, substitution, ellipsis, conjunctions and lexical cohesion.

11. Provide examples to which all, or at least most, of the students in the target audience can relate.

12. Ensure that the text contains all and only those pieces of information that are necessary for the relevant message to be conveyed.

13. Obtain information on the target audience (in this case including, for example, information on the learners' ages, educational backgrounds, L1s, levels of L2 English proficiency, and literacy skills) before starting the writing process, and keep this information in mind throughout.

14. Introduce specialist terms in a systematic way. First, specialist terms should only be used when they are essential for the students' comprehension of new concepts. Second, a term should be explained very carefully when it is used for the first time, i.e. when giving the purpose, definition and examples of a concept. Third, reminders should be given at certain points, e.g. when the term is used again. Fourth, the number of technical terms in a paragraph should be limited. Fifth, alternative technical terms for the same concept should not be used. Finally, once a technical term is introduced, avoid reverting to the original (non-technical) term.

15. Use precise words and avoid those that are general, abstract or vague.

16. Use the correct tone; strike a balance between assertiveness and accessibility.

17. Use the dialogic style; write a conversation-in-print.

18. To avoid offending the reader, underplay your assertiveness at times by using modal verbs and adverbs; leave room for tentativeness.

19. Interact with the students.

20. Use contractions.

21. Ensure that the use of personal pronouns is unambiguous.

22. Invite your readers; do not instruct them.

23. Keep vocabulary and sentence constructions simple while at the same time stimulating the students and maintaining their interest.

24. Use a "light touch" by being serious but not solemn, and by being precise, particular and penetrating but not pedantic.

25. Make conscious decisions about which syntactic structures to use. Although the length of sentences should vary within a text, sentences should in general be kept relatively short and follow a simple pattern. 


\section{Suggestions for further research}

The limited scope of this study did not allow for the analysis of more than three study guides. Analysing more than three study guides and comparing those used within the same faculty/department might allow one to rank the linguistic criteria according to their relative importance, and to identify additional linguistic criteria.

Furthermore, this research could have been triangulated by conducting a survey with students to assess which study guides they prefer in order to determine which linguistic criteria are critical from a student's perspective. Feedback from students would allow one to assess how they experienced the study guides.

It would also be useful to compare the marks achieved for different courses offered as part of the same degree, in order to determine what the relationship is between (i) the extent to which a study guide adheres to the linguistic criteria identified here, (ii) how the study guide is perceived and experienced by the students, and (iii) what marks students receive for a particular assignment or exam based on the study guide.

It should be noted that, due to practical reasons, it was not possible for me to collect student feedback for the purposes of this research. In this regard, I would like to obtain such feedback in follow-up research.

Other avenues for further research include:

a. Assessing whether or not the presence or absence of the aforementioned linguistic criteria, as a group or individually, makes a difference in the student's comprehension of the content;

b. Assessing how essential the identified linguistic criteria are for study material for second-year, third-year, and postgraduate students;

c. Assessing the effectiveness of the identified linguistic criteria in other genres, e.g. academic articles and textbooks;

d. Assessing the effectiveness of the identified linguistic criteria in different academic disciplines, and

e. Comparing the writing strategies of lecturers who are L1 speakers of English with the writing strategies of lecturers who are L2 speakers of English.

\section{Conclusion}

The research reported in this article contributes, if only in a small way, to our understanding of what is involved in writing an effective study guide for a DLI. This is valuable in light of the central role that the study guide plays at DLIs, and the important role that DLIs play in the South African context, especially in allowing people to attend a tertiary academic institution in cases where it would not have been possible for them to receive tertiary education through a residential university. 


\section{Acknowledgement}

I would like to thank the supervisor of my MPhil, Dr Simone Conradie from the Department of General Linguistics at Stellenbosch University for her insight into my thesis that eventually became this article.

\section{References}

Abdi, R., M.T. Rizi and M. Tavakoli. 2010. The cooperative principle in discourse communities and genres: A framework for the use of metadiscourse. Journal of Pragmatics 42(6): 16691679.

Atkinson, D. 2004. Contrasting rhetorics/Contrasting cultures: Why contrastive rhetoric needs a better conceptualization of culture. Journal of English for Academic Purposes 3(4): 277-289.

Bourdieu, P. and L.J.D. Wacquant. 1992. An invitation to reflexive sociology. Cambridge: Polity Press.

Carroll, J.B. (ed.) 1956. Language, thought, and reality: Selected writings of Benjamin Lee Whorf. Cambridge, MA: MIT Press.

Collier, M.J. 2003. Understanding cultural identities in intercultural communication: A ten-step inventory. In L.A. Samovar and R.E. Porter (eds.) Intercultural communication: A reader. Wadsworth: Thomson. pp. 412-429.

Connor, U. 1996. Contrastive rhetoric: Cross-cultural aspects of second-language writing. New York: Cambridge University Press.

Duszak, A. 1997. Cross-cultural academic communication: A discourse-community view. In A. Duszak (ed.) Trends in linguistics: Studies and monographs 104. Berlin/New York: Mouton de Gruyter. pp. 11-40.

Enkvist, N.E. 1990. Seven problems in the study of coherence and interpretability. In U. Connor and A.M. Johns (eds.) Coherence in writing: Research and pedagogical perspectives. Alexandria: Teachers of English to Speakers of Other Languages, Inc. pp. 9-28.

Erben, T. and S. Fagan. 1995. Being a non-English speaking background (NESB) student and distance education. Understanding a process of in- and exclusion. In F. Nouwens (ed.) Distance education: Crossing frontiers: Proceedings of the $12^{\text {th }}$ biennial forum of the Open and Distance Learning Association of Australia. Vanuatu (Sept.), Rockhampton: Central Queensland University. pp. 57-59.

Guirdham, M. 1999. Communicating across cultures. London: Macmillan Press.

Halliday, M.A.K. 1973. Explorations in the functions of language. London: Arnold.

Halliday, M.A.K. and R. Hasan. 1976. Cohesion in English. London: Longman. 
Halliday, M.A.K. and R. Hasan. 1989. Language, context, and text: Aspects of language in a social-semiotic perspective. Oxford: Oxford University Press.

Hofstede, G. 1986. Cultural differences in teaching and learning. International Journal of Intercultural Relations 10(2): 301-320.

Hofstede, G., G.J. Hofstede and M. Minkov. 2010. Cultures and organizations: Software of the mind. New York: McGraw Hill.

Holliday, A.R. 1994. Appropriate methodology and social context. Cambridge: Cambridge University Press.

Hyland, K. 2005. Stance and engagement: A model of interaction in academic discourse. Discourse Studies 7(2): 173-192.

Hyland, K. 2009. Academic discourse. London: Continuum.

Hyland, K and P. Tse. 2004. Metadiscourse in academic writing: A reappraisal. Applied Linguistics 25(2): 156-177.

Johns, A.M. 1986. Coherence and academic writing: Some definitions and suggestions for teaching. TESOL Quarterly 20(2): 247-265.

Johns, A.M. 1990. Coherence as a cultural phenomenon: Employing ethnographic principles in the academic milieu. In U. Connor and A.M. Johns (eds.) Coherence in writing: Research and pedagogical perspectives. Alexandria: Teachers of English to Speakers of Other Languages, Inc. pp. 209-226.

Jung, E.H. 2006. Misunderstanding of academic monologues by non-native speakers of English. Journal of Pragmatics 38(11): 1929-1942.

Kaplan, R.B. 1966. Cultural thought patterns in inter-cultural education. Language Learning 16(1-2): 1-20.

Kaschula, R. and C. Anthonissen. 1995. Communicating across cultures in South Africa. Johannesburg: Hodder and Stoughton.

Kember, D. 1991. Writing study guides. Bristol: Technical and Educational Services Ltd.

Kreutz, H. and A. Harres. 1997. Some observations on the distribution and function of hedging in German and English academic writing. In A. Duszak (ed). Trends in linguistics: Studies and monographs 104. Berlin/New York: Mouton de Gruyter. pp. 181-202.

Lewis, R and N. Paine. 1985. How to communicate with the learner. Huddersfield: H. Charlesworth \& Co. Ltd.

Mandelbaum, D.G. (ed.) 1983. Selected writings of Edward Sapir in language, culture and personality. Berkeley: University of California Press. 
Mauranen, A. 1993. Cultural differences in academic rhetoric: A textlinguistic study. Frankfort am Main: Peter Lang.

Ozuru, Y., K. Dempsey and D.S. McNamara. 2009. Prior knowledge, reading skill, and text cohesion in the comprehension of science texts. Learning and Instruction 19: 228-242.

Qakisa-Makoe, M. 2005. Reaching out: Supporting black learners in distance education. Progressio 27(1\&2): 44-61.

Rowntree, D. 1981. Developing courses for students. Maidenhead: McGraw-Hill.

Rowntree, D. 1990. Teaching through self-instruction. London: Kogan.

Sonnekus, I.P., W. Louw and H. Wilson. 2006. Emergent learner support at University of South Africa: An informal report. Progressio 28(1\&2): 44-53.

University of South Africa (Unisa). 2008. Open distance learning policy. Available online: http://www.unisa.ac.za/cmsys/staff/contents/departments/tuition_policies/docs/OpenDistance Learning_Council3Oct08.pdf (Accessed 25 March 2014).

University of South Africa (Unisa). 2014. Department of institutional information and analysis portal. Available online: http://heda.unisa.ac.za/indicatordashboard/default.aspx (Accessed 17 August 2014).

Ventola, E. 1996. Packing and unpacking of information in academic texts. In E. Ventola and A. Mauranen (eds.) Academic writing: Intercultural and textual issues. Amsterdam: John Benjamin's Publishing Company. pp. 153-194.

Ventola, E. 1997. Modalization: Probability - an exploration into its role in academic writing. In A. Duszak (ed.) Trends in linguistics: Studies and monographs 104. Berlin/New York: Mouton de Gruyter. pp. 157-180.

Vergie, M. 2010. Effective Language Use in Academic Study Material for L2 Speakers of English at a Distance Learning Institution. MPhil dissertation, University of Stellenbosch.

Xing, M., J. Wang and K. Spencer. 2008. Raising students' awareness of cross-cultural contrastive rhetoric in English writing via an E-learning course. Language Learning and Technology 12(2): 71-93. 